\title{
ASPECTOS DE SAUDE NA ROTINA DA CRECHE E O PAPEL DO CUIDADOR DA CRIANÇA: RELATO DE EXPERIÊNCIA
}

\section{HEALTH ASPECTS IN THE CRECHE ROUTINE AND THE FUNCTTON OF THE CHILD CAREGIVER: AN EXPERIMENT REPORT}

Maria Cecília Leile de Moraes ${ }^{1}$

LEITE DE MORAES, M. C. Aspectos de Saúde na Rotina da Creche e o Papel do Cuidador da Criança: Relato de Experiência. Rev. Bras. Cresc. Desenv. Hum., S. Paulo, 7 (1), 1997.

\begin{abstract}
Resumo: Este artigo é uma leitura sobre as ações rotineiras da creche e suas relações com o aspecto de saúde. Esta última é analisada como um substrato amplo que perrneia todo o cotidiano desta instituição. Observa-se, ainda, neste contexto as relações da creche e da família. Aborda a importância do intercâmbio entre estes dois componentes, levando-se em conta que o ator principal é a criança. Discute-se, ainda, a relevância do papel do "cuidador" e a necessidade de implementos na sua formação inicial, assim como constantes reciclagens.
\end{abstract}

Palavras-chave: creche, criança, familia, saúde.

\section{INTRODUÇÃO}

Desde a incorporação da instituição creche em algumas metrópoles do Brasil emergiram, e ainda emergem, vários debates sobre as suas diferentes funções. Um dos grandes debates parece estar associado ao próprio papel da creche e o comportamento da familia frente a esta. MOTTA (1991) observa que as relações da mulher/mãe com a instituição são bastante difíceis e que a convivência entre ambas se agravam na vivência cotidiana. Outro importante debate decorre da própria função da creche. Durante seu funcionamento, aproximadamente doze horas, o que corresponde a dois terços de vida acordada da criança (SIQUEIRA, 1989), 0 equipamento responde integralmente por este indivíduo, ou seja, pela guarda, alimentação e cuidados da criança. Entre estes cuidados destaca-se a saúde, porém, levando-se em conta o conceito vigente de saúde, adotado pela ORGANIZAÇÃO MUNDIAL, quer-se registrar sob a ética da experiência de trabalho, a diferença entre esta definição e a realidade. Saú- de é um conjunto de fatores, uma tríade entre o físico, o mental e o social, não cabendo, a nenhum destes fatores, ter domínio sobre o outro. Da mesma forma, neste texto, quer-se destacar o papel do "cuidador" da criança integral e levantar aspectos considerados relevantes para o seu desempenho neste complicado e ainda pouco entendido contexto.

\section{CRECHE}

A partir de 1943, a creche "surge”, legalmente, como um serviço de suporte para mulheres da classe trabalhadora, no próprio local do emprego, sob a égide da Consolidação das Leis do Trabalho. Ao longo dos anos a concepção vai se alterando, existe um momento de benemerência, filantropia, onde o usuário é a criança pobre. De acordo com MOTTA (1996), este significado é tão forte que, em períodos mais atuais, as classes mais privilegiadas o trocam por berçário e escolinha, entre outros. Ainda de acordo com a

1 Terapêuta Ocupacional, Mcstre em Saúde Pública pela Faculdade de Saúde Pública/USP, pesquisadora do Centro de Estudos do Crescimcnto e Dcsenvolvimento Humano.

End.: Av. Dr. Arnaldo, 715, subsolo. sala 21, São Paulo - SP - CEP: 01246-904 - Telefax (011) 3061 -3572. 
autora, contemporaneamente a visão assistencialista se transforma em atitude e linguagem mais tecnicistas.

Para LEFÈVRE (1989). a creche faz parte do mundo que nossas crianças vivem. Destaca, também, que a creche não é melhor nem pior do que a família, existe na verdade, uma confusão entre os papéis de uma e de outra: mae é mãe, pajem é pajem família é família c creche é creche. Existem duas entidades distintas; a criança é um na família e é coletivo na creche, é filha na família e é usuária na creche, pertence judicialmente à família e não pertence à creche.

ROSSETTI-FERREIRA (1994) aponta para o fato de que, atualmente, mesmo as mulheres que não trabalham fora, também têm procurado um espaço de socialização para as crianças, visto que, estas contam com poucos recursos domésticos. Fala-se de espaço de crescimento e desenvolvimento do ser humano criança (SIQUEIRA 1989).

\section{SAÚDE/CRECHE - “CUIDADOR”/FAMÍLIA}

Em casa, a criança desempenha uma série de ações rotineiras que são reproduzidas na creche. Estas ações estão associadas ao sistema de cuidados englobando: alimentação, higiene pessoal, brincar e também prevenção de acidentes. Visualizar a creche com esta amplitude, integral e presente, na vida da criança moderna, implica em indagar-se sobre o fator saúde neste contexto.

O conceito da Organização Mundial para saúde afirma que esta é bem-estar físico, mental e social. Abordar a definição de saúde em um só destes aspectos é não apreender o ser humano na sua totalidade, é apenas tratar parcialmente a questão (MARTINS, 1986). LISBOA (1993) trata da criança como ser holístico, ou seja, uma unidade bio-psicosocial.

A creche é, ou deveria ser, um espaço sócio-educativo saudável para crianças pequenas. Se é saudável deve ter entre suas funções o cuidado da saúde do seu usuário e incorporar este conceito aos cuidados do equipamento. Para esta reflexão, toma-se como ponto de partida desta discussão a rotina da creche.

Pela manhã, há uma triagem feita pelo profissional de saúde. Verifica-se se a criança está doente, e se caso isto acontecer ela, provavelmente, será impedida de ficar na creche. Em muitos casos poderá ser uma medida acertada, embora muitas vezes se observe um certo exagero. Febrículas, dores de ouvido e garganta têm o "visto negado”. Dia de trabalho perdido pela mãe/pai, visita ao médico que avalia a não gravidade do caso e muitas vezes a frustração, tanto familiar como institucional pelo acontecido. Há de se ter sensibilidade, os processos infecto-contagiosos existem de fato, quando começam a freqüentar a creche o organismo da criança entra em contato com vírus e bactérias que podem causar doenças. SIQUEIRA (1989) chama este processo de experiência infecciosa porém, de maneira genérica após um certo período haverá uma adaptação orgânica sem danos para a saúde.

Um dos primeiros procedimentos, quando a criança começa a freqüentar a creche, é avisar aos familiares que fica proibido que esta leve objetos pessoais tais como: cobertores, travesseiros ou bichos de pelúcia. Esta medida tem como objetivo preservar aspectos de higiene, já que estes objetos costumam passar pelas mãos, boca, e chão, além do que, por vezes, se compartilha a experiência com os novos colegas; embora, a mesma experiência possa se tornar um conflito porque, muitas vezes, não existe a vontade de compartilhar o objeto. Destaca-se este aspecto dos objetos pelo significado que ele tem para a criança, de acordo com a teoria de Winnicott, estes são objetos transacionais. Para o seu dono, eles trazem a lembrança do acolhimento materno e boas sensações: calor, maciez além do que têm caráter confortados e são, também, essenciais para o processo de individualização. Acredita-se que compreendendo o valor do objeto seja possível avaliar a mutilação a qual se submete a criança ao arrancar-lhe tal valor, da mesma forma não se pode perder de vista a necessidade que ela possa sentir do mesmo por ocasião de vivência tão nova, diferente e até difícil a entrada na creche - fora do seu "locus" seu "habitat", com pessoas diferentes (MORAES, 1997). O fator higiene é importantíssimo mas a preservação do afetivo e a saúde mental também o são. Quanto ao conflito entre crianças quer-se crer que o “cuidador”, dependendo da necessidade, seja capaz de mediar a situação.

No quesito alimentação deve-se pensar que muito do que será servido para a criança é novidade, e como tudo que é novo pode causar estranheza. Não se pode afinmar que os alimentos servidos na creche estejam incorporados à cultura local: o suco, as verduras, os legumes, a textura do arroz, dentre outros.

Na medida em que os alimentos forem visualmente atrativos e possuírem odores estimulantes ao paladar este processo de incorporação de novos alimentos pode ser bastante facilitado.

Não se trata de fazer pratos decorados. mas, comida com aspecto feio, inodora e macilenta pode causar repulsa para a criança. A apresentação dos pratos, o cuidado ao servir, o diálogo entre o "cuidador" e a criança sobre os alimentos 
contemplam aspectos tanto de saúde como de educação e socialização. Respeitar o ritmo da criança para comer, não passar todo o tempo gritando para que se coma depressa, engolir. ou empurrar a comida garganta abaixo são procedimentos execráveis. São várias crianças, existe o fator “stress (MORAES \& D’ANTINO, 1989)” porém este trabalho requer pessoas com algumas características: paciência, se importar com o outro, entre outras (GHELER \& RABINOVICH. 1989).

$\mathrm{Na}$ rotina da creche existe o horário do sono. É altamente recomendável que a criança durma durante o dia, é um momento de relaxamento onde o cérebro descansa. Porém, não se pode exigir que todas as crianças tenham o mesmo ritmo e duramam neste horário. Algumas crianças quando começam a freqüentar a creche ou não possuem este hábito ou, simplesmente. não conseguem dormir. Cita-se que em certos locais, obriga-se a criança a ficar em silêncio no escuro, ou ainda lhe cobrem a cabeça para que o sono venha. Não se compreende tal atitude quando se fala em espaço saudável. Atividades que acalmam como ouvir estórias ou detenninado tipo de música podem ser soluções.

A higiene na creche deve seguir determinados padrões e estes repassados para as crianças através de hábitos como: lavar as mãos, escovar os dentes, tomar banho. Podem ocorrer casos, em que a criança não venha com as roupas limpas. ou outros, em que ela mesma não esteja limpa, segundo o padrão da creche. Nestes casos observa-se, geralmente, a existência de conflito. Na maioria das vezes, o "cuidador” vai acusar a família de não seguir os procedimentos de higiene preconizados pelo equipamento. Dependendo do local onde vai estar instalada a creche, poderá haver falta de água crônica e, dependendo das condições da família, este problema pode ser agravado. Incorporar hábitos saudáveis de higiene para criança é um dos papéis da creche, mas atitudes higienistas extremas, como fazer a criança voltar para casa porque está com as unhas sem cortar, ou porque o perfume destoa com o ambiente não será, de forma alguma, um método correcional adequado.

Outro ponto que merece atenção é o brincar. Esta é a atividade mais dignificante da infância, onde a criança é capaz de se colocar, colocar o seu mundo e transformá-lo (MORAES, 1997). Aspectos sensoriais, motores, afetivos, sociais e lingüísticos são enriquecidos com a atividade de brincar (PENTEADO et al., 1996). O "nao brincar” deve levantar tantas interrogações como o não se alimentar. Uma criança que passa seu tempo apática, sem imaginar, sem criar, sem falar sozinha, sem participar das brincadeiras do grupo depen- dendo do seu estágio de desenvolvimento, deve ser observada mais de perto, com mais desvelo pelo seu “cuidador”. Não se fala em estar perto, papeando com os outros “cuidadores” enquanto as crianças estão lá, fala-se de participação do adulto, - cooperação na atividade e sugestões.

Afirma-se também que, a alimentação, o sono, o brincar, entre outros, poderiam ser melhor trabalhados, se houvesse a informação, isto é, um real intercâmbio com a família. Nada do que se diz neste parágrafo serve como justificativa para os fatos citados como inadequados, porém alguém da família da criança poderia fornecer subsídios sobre estes seus hábitos rotineiros. Não se fala em fichas ou inquéritos formais, mas em período de adaptação com a presença se possível de um familiar próximo, pois além da informação haveria um fortalecimento dos laços instituição e família, comprometimento de ambas as partes, responsabilidade compartilhada e relação de confiança.

As mudanças alimentares na vida da criança como introdução de alimentos sólidos, ou ainda a fase de troca do uso de fraldas pelo uso do vaso sanitário, poderiam ser menos complicadas se houvesse a participação da família.

De outro lado a família que coloca seu filho em uma creche tem que conhecer as suas rotinas e, quando necessário, se adaptar a algumas delas. Exigir cuidados especiais durante todo o tempo, proibir que o filho tenha contato com a água, ou ainda, que fique descalço, não são medidas que preservam a saúde da criança. Ao cumpri-la, pelo contrário, a creche torna esta criança marginalizada dentro do grupo onde, agora, está inserida.

Todo este contexto é bastante polêmico podendo ainda avançar-se nas posturas de higiene próprias de quem cuida da criança; ou ainda na medicalização do local por parte do profissional de saúde. Mas, voltando a proposta inicial desta análise cabe agora uma discussão sobre o “cuidador” da criança.

De forma genérica, tem se observado que as pessoas que trabalham com as crianças pequenas têm origem, formação e experiência bastante diversificadas. Alguns trazem na bagagem diploma de nível superior em área de saúde ou educação, quando não ambos; outros trazem a vivência dos cuidados com crianças de sua própria família, outros, ainda, experiências de cuidados infantis domésticos. Isto significa que não existe uma linha de trabalho que norteie o grupo de “cuidadores", existem sim algumas regras tiradas da experiência vivida em escolas e até em creches mas não uma formação específica para este profissional tão importante; alguém que vai estar 
trabalhando com saúde física, mental e social. Social no sentido mais amplo, o que trata do desenvolvimento da pessoa, e isto acaba resultando em cidadania. Usa-se, aqui propositadamente o termo "cuidados", porque não se trata de um professor ou de um tutor. E, realmente, alguém que cuida, que ajuda na construção da pessoa, e mesmo nos dias de hoje não existe nenhuma terminologia específica para este papel. Na creche não é uma função específica do diretor, ou do monitor, ou o do cozinheiro, ou do auxiliar de enfermagem, são todos estes, ou seja, os que escolheram trabalhar com crianças pequenas.

GHELER \& RABINOVICH (1989) indicam aspectos importantes para o desempenho deste papel. Um dos fatores relevantes para o desenvolvimento de uma criança é sua interação com o meio ambiente, e no início da vida esta mediação é feita com a ajuda do adulto (“cuidados”), desta forma, parte importante cabe a inter-relação adulto x criança e criança $\mathrm{x}$ adulto. Esta relação é essencial para o processo de humanização, sendo que humanizar-se é desenvolver o potencial de aprendizagem para pertencer à raça humana e à sua cultura. Para isto é necessário a figura de um adulto capaz de cumprir a rotina da vida da criança, ou seja, dar cuidados contínuos e sistemáticos.

LISBOA (1993) afirma que a criança pequena é totalmente dependente necessitando do apoio e carinho das pessoas que a cercam.

No aspecto pessoal o "cuidador" deveria ser uma pessoa capaz de proporcionar suporte afetivo, ter relações de troca com a criança e ser tolerante.

Quanto à instituição, ainda segundo GHELER RABINOVICH (1989), esta tem o papel de manter a rotina, ter um quadro estável de funcionários e responder por uma sistematização de cuidados que garantam a continuidade do atendimento.

MORAES \& D’ANTINO (1989) discutem que a saúde na creche deve, também, se estender aos cuidados com os funcionários visto que este é um trabalho com grande exigência e desgaste. Não se pode deixar de citar que a rotina é parte importante do serviço prestado pela creche porém o bom senso deve permear o trabalho.

\section{CONSIDERAÇÕES GERAIS}

Desde a década de 80, o Centro de Estudos do Crescimento e do Desenvolvimento do ser Humano vem se manifestando sobre a importância da capacitação do pessoal de creche. Discute-se sobre a implantação de cursos de educação formal para o profissional “cuidador”, já que a creche não é uma mini escola e o cuidado com a criança de 0 a 6 anos tem grande especificidade.

A creche é um local de crescimento e desenvolvimento do ser humano e, para tal função requer seres humanos capazes de responder à proposta de "ser agente de promoção de crescimento e desenvolvimento”. Qualidades pessoais, perfis, são partes importantes, porém a formação, o conhecimento que alicercem a vivência e experiência individuais são fundamentais. A formação e a reciclagem devem fazer parte do preparo do profissional da creche. Conhecer o "ser criança”, conhecer a cultura local, as propostas e programas do equipamento requer instrução. Ser capaz de obter inforrnações da família, ser atento, observador, incorporar outros conhecimentos e não ser dono do saber técnico e absoluto fazem parte desta formação. Gerir uma creche saudável é diferente de, simplesmente, gerir uma creche. Faz-se necessário documentar as experiências que deram certo, assim como novos programas. O fluxo de informações assim como o intercambio inter equipamentos podem ser espaços interessantes.

Todo o trabalho deve ser pautado na construção do ser humano, incluindo cidadania e futura inserção social no seu meio, isto tudo centrado na tríade do bem-estar da criança.

A creche, independente da nomenclatura que receba é um equipamento que veio para ficar, porisso acompanhando toda modernização cultural, os constantes avanços aos quais o mundo está sempre sujeito, há de se aperfeiçoar o tipo de atendimento proposto. A multi e interdisciplinaridade dos seus componentes, a troca de experiências entre equipamentos, sejam da área pública como particular, e o relato de diferentes enfoques são de grande valia.

A concepção da creche, com certeza, vai se alterar da mesma forma que as "novas crianças” irão avançar em função da gama de informações que o mundo Ihes oferece. Porém, a creche permanece e a criança continua a ser criança. Daí a necessidade premente da fonnação do adulto “cuidador”. Todo funcionário é promotor e provedor de saúde e a pretensão do trabalho deve ser proporcionar atendimento de qualidade. 


\begin{abstract}
This article is a review about the crèche routines and their association with health aspects. Health is analyzed as a substratum that permeates the daily routine of the crèche. In th is context the relationship between the crèche and the family is observed. The importance of the interchange between them is analysed, taking into account that the main element is the child. The article also discusses the significance of the role of "caregiver" and the need for implements in his/her initial development, as well as the need for refresher courses throu hout his/her practice.
\end{abstract}

Key-words: crèche, child, family, health.

\section{REFERÊNCIAS BIBLIOGRÁFICAS}

GHELER, R.; RABINOVICH, E. P. Recursos humanos em creche: promoção do desenvolvimento. Ensaio - perfil do profissional nessa área. (Palestra proferida no Encontro de Creches do $A B C D R$ - relatório $M R$ ) - São Paulo, 1989.

LEFÈVRE, F. Modelo de creche. (Palestra proferida no Encontro de Creches do ABCD MR) - Relatório. São Paulo, 1989.

LISBOA, A. M. J. Formação de recursos humanos para o atendimento à saúde da criança de 0 a 6 anos. Rev. Bras. Cresc. Desenv. Hum., São Paulo, 3 (1): 128-133, 1993.

MARTINS, I. S. Palestra proferida no Encontro sobre Creches (1986).

MORAES, M. C. LEITE DE.; D'ANTINO, M. E. Gerenciamento. (Palestra proferida no Encontro de Creches do ABCD - MR) - Relatório. São Paulo, 1989.

MORAES, M. C. LEITE DE. Avaliação perceptomotora em crianças, com cerca de três anos de idade, nascidas de mães portadoras de hipertensão arterial. São Paulo, 1997. [Dissertação de Mestrado - Faculdade de Saúde Pública da USP].
MOTTA, M. A. Mãe-creche: relações ambivalentes. Um estudo de casos sobre a representaçao de usuárias. Rev. Bras. Cresc. Desenv. Hum., S.Paulo, 1 (1): 113-114, 1991.

MOTTA, M. A. A creche: uma instituição em busca de identidade. Rev. Bras. Cresc. Desenv. Hum., São Paulo, 6 (1): 14-18, 1996.

OLIVEIRA, D. C. A promoção do crescimento da criança. (Palestra proferida no Encontro de Creches do $A B C D$ - MR) - Relatório. São Paulo, 1989.

PENTEADO. R. Z. et al. Ações educativas em saúde da criança: o brincar enquanto recurso para participação da familia. Rev. Bras. Cres. Desenv. Hum., São Paulo, 6 (1/2): 49-56,1996.

ROSSETI - FERREIRA, M. C. et al. A creche enquanto contexto possível de desenvolvimento da criança pequena. Rev. Bras. Cresc. Desenv. Hum., São Paulo, 4 (2): 35-40, 1994.

SIQUEIRA, A. A. F. Promoção de saúde em creche. (Palestra proferida no Encontro de Creches do $A B C D-M R)$ - Relatório. São Paulo, 1989.

Recebido em: 02/02/9S Aprovado em: 04/03/98 